\title{
Chromosomal characteristics and distribution of rDNA sequences in the brook trout Salvelinus fontinalis (Mitchill, 1814)
}

\author{
A. Śliwińska-Jewsiewicka ${ }^{1} \cdot$ M. Kuciński ${ }^{2}$ L. Kirtiklis ${ }^{3} \cdot$ S. Dobosz ${ }^{4} \cdot$ \\ K. Ocalewicz ${ }^{5}$ Malgorzata Jankun ${ }^{2}$
}

Received: 11 March 2015 / Accepted: 4 May 2015/Published online: 10 May 2015

(C) The Author(s) 2015. This article is published with open access at Springerlink.com

\begin{abstract}
Brook trout Salvelinus fontinalis (Mitchill, 1814) chromosomes have been analyzed using conventional and molecular cytogenetic techniques enabling characteristics and chromosomal location of heterochromatin, nucleolus organizer regions (NORs), ribosomal RNA-encoding genes and telomeric DNA sequences. The C-banding and chromosome digestion with the restriction endonucleases demonstrated distribution and heterogeneity of the heterochromatin in the brook trout genome. DNA sequences of the ribosomal RNA genes, namely the nucleolus-forming $28 \mathrm{~S}$ (major) and non-nucleolus-forming 5S (minor) rDNAs, were physically mapped using fluorescence in situ hybridization (FISH) and primed in situ labelling. The minor rDNA locus was located on the subtelo-acrocentric chromosome pair No. 9, whereas the major rDNA loci were dispersed on 14 chromosome pairs, showing a considerable inter-individual variation in the number and location. The major and minor rDNA loci were
\end{abstract}

Malgorzata Jankun

mjpw@uwm.edu.pl

1 Department of Human Histology and Embryology, Faculty of Medical Sciences, University of Warmia and Mazury in Olsztyn, Olsztyn, Poland

2 Department of Ichthyology, Faculty of Environmental Sciences, University of Warmia and Mazury in Olsztyn, Olsztyn, Poland

3 Department of Zoology, Faculty of Biology and Biotechnology, University of Warmia and Mazury in Olsztyn, Olsztyn, Poland

4 Department of Salmonid Research, Inland Fisheries Institute in Olsztyn, Olsztyn, Poland

5 Department of Marine Biology and Ecology, Faculty of Oceanography and Geography, University of Gdansk, Gdańsk, Poland located at different chromosomes. Multichromosomal location (3-6 sites) of the NORs was demonstrated by silver nitrate $\left(\mathrm{AgNO}_{3}\right)$ impregnation. All Ag-positive i.e. active NORs corresponded to the GC-rich blocks of heterochromatin. FISH with telomeric probe showed the presence of the interstitial telomeric site (ITS) adjacent to the NOR/28S rDNA site on the chromosome 11. This ITS was presumably remnant of the chromosome rearrangement(s) leading to the genomic redistribution of the rDNA sequences. Comparative analysis of the cytogenetic data among several related salmonid species confirmed huge variation in the number and the chromosomal location of rRNA gene clusters in the Salvelinus genome.

Keywords Salmonid cytogenetics - Chromosome banding $\cdot$ FISH $\cdot$ Karyotype variability $\cdot$ NORs $\cdot$ Telomeres

\section{Introduction}

It is considered that the whole-genome duplication (WGD) event dated 88-103 Mya (Macqueen and Johnston 2014) took place in the common ancestor of the Salmonidae and provided the first tetraploid salmonid karyotype composed of about 100 telocentric chromosomes (Phillips and Ráb 2001). To recover disomic segregation duplicated salmonid genome has experienced several chromosomal rearrangements mostly fusions leading to the huge diversification of the karyotypes and adaptive radiations among the extant salmonid species (Phillips and Ráb 2001). Even though, the rediploidization process has not been fully completed yet what is evidenced by the tetrasomic inheritance of some loci (Sakamoto et al. 2000), the formation of the multivalents at meiosis (Oliveira et al. 1995) and the intraspecies chromosome and chromosome arm number variations 
observed in the representatives of Coregoninae, Salmoninae and Thymallinae subfamilies (Jankun et al. 2007; Caputo et al. 2009; Ocalewicz and Dobosz 2009; Ocalewicz et al. 2013). Apart from the major rearrangements concerning whole chromosomes, translocations, inversions, duplications and deletions of the chromosomal segments have also accompanied evolution of the salmonid karyotypes and resulted in the length and structure polymorphisms of the individual chromosomes.

The genus Salvelinus is comprised of three sub-genera: Salvethymus, Baione, and Salvelinus (Nelson 2006). Although, more than 50 species of genus Salvelinus has been recognized and described (FishBase 2015) so far only 12 of them have been cytogenetically studied (Arai 2011). In these species, chromosome and chromosome arm numbers range from 76 to 84 and from 98 to 102, respectively and the polymorphisms of the chromosome length and structure are frequently observed (Phillips and Ihssen 1986; Phillips et al. 1989; Fujiwara et al. 1998; Phillips and Ráb 2001). Sex chromosomes have been described in only two Salvelinus species (both from subgenus Baione); the lake trout (Salvelinus namaycush) (Phillips and Ihssen 1985a) and the brook trout (Ocalewicz et al. 2004). Though brook trout was a subject of a number of aquaculture issues (Fischer et al. 2009), genome manipulations (Michalik et al. 2014), population genetics (Danzmann et al. 1998) and phylogenetic studies (Grewe et al. 1990) chromosomal and genomic organization of this salmonid species has been superficially studied to date. Brook trout is the only known salmonid species without described polymorphism regarding diploid chromosome number $(2 \mathrm{n}=84)$ and chromosome arm number $(\mathrm{FN}=100)$ (Lee and Wright 1981). On the other hand, brook trout chromosomes exhibit inter-individual variation in the size and position of the GC-rich DNA segments (Phillips and Ihssen 1985b; Phillips and Reed 1996; Ocalewicz et al. 2004) that in fishes are associated with the NORs (Amemiya and Gold 1986; Ráb et al. 1999).

In the present paper we combined conventional and molecular cytogenetic protocols to analyse the brook trout chromosomes in order to explain the extensive variations among the chromatin components of its genome. Combination of silver nitrate $\left(\mathrm{AgNO}_{3}\right)$, chromomycin $\mathrm{A}_{3}$ $\left(\mathrm{CMA}_{3}\right), 4^{\prime}, 6$-diamidino-2-fenylindole (DAPI) staining, C-banding, restriction endonuclease (RE) digestion, fluorescence in situ hybridization (FISH), and primed in situ (PRINS) labelling techniques applied to the brook trout chromosomes enabled chromosomal localization of the major and minor rRNA genes and cytogenetic characteristics of the chromatin overlapping these regions. Extensive polymorphism(s) related to the location of the GCrich blocks and activity of the NORs observed among studied brook trout individuals has been discussed in the context of enormous dispersion of the 28S rDNA sequences and interstitial location of the telomeric DNA repeats.

\section{Materials and methods}

\section{Materials}

Twenty-two 1-year-old brook trout individuals (10 females, 12 males) were studied cytogenetically. Fish were obtained from an experimental fish farm of the Department of Salmonid Research, Inland Fisheries Institute in Olsztyn, Rutki, Poland. The phenotypic sex was determined in the course of the phase contrast microscope analysis of the gonad tissue squashed with a cover slip.

\section{Chromosome preparation}

Chromosomes were prepared from the pooled cephalic kidney cells by conventional air-drying technique by Jankun et al. (1998). Briefly, fishes were injected with $0.1 \%$ colchicine solution ( $1 \mathrm{ml} / 100 \mathrm{~g}$ of body weight). After $60 \mathrm{~min}$ fishes were sacrificed by overdose of the anesthetic 2-phenoxyethanol (Sigma-Aldrich, USA). Kidney tissue was removed, dissected in $0.075 \mathrm{M} \mathrm{KCl}$ and cell suspension free of tissue fragments was hypotonized for $60 \mathrm{~min}$ in $0.075 \mathrm{M} \mathrm{KCl}$, prefixed $(5 \mathrm{~min})$ and fixed in methanol: acetic acid fixative $(3: 1)$, washed twice in fixative, and finally spread onto the microscopic slides.

\section{Banding techniques}

The constitutive heterochromatin blocks were identified using C-banding technique by Sumner (1972) with some modifications. Briefly, slides were treated in $0.1 \mathrm{~N}$ hydrochloric acid for $3 \mathrm{~min}$, dipped in saturated $\mathrm{Ba}(\mathrm{OH})_{2}$ at $50{ }^{\circ} \mathrm{C}$ for $90 \mathrm{~s}$. and incubated in $2 \times \mathrm{SSC}$ at $65^{\circ} \mathrm{C}$ for $2 \mathrm{~h}$. After washing in distilled water slides were stained with $5 \%$ Giemsa solution for $5 \mathrm{~min}$ in $\mathrm{pH}$ 6.8. For identification of AT-rich chromatin regions, chromosomes were stained with DAPI. Three drops of antifade solution Vectashield (Vector, Burlingame, USA) containing DAPI $(1.5 \mu \mathrm{g} / \mathrm{ml})$ were dropped onto a slide and covered with a coverslip. Restriction endonuclease (RE) banding was performed by digestion of few hours old spread metaphase chromosomes with AluI, DdeI, HaeIII, HinfI and MboI (Promega), according to Jankun et al. (2004). Briefly, restriction enzymes suspended in the appropriate buffers were applied in different concentrations to the air-dried cell suspension as shown in Table 1. Then, slides were incubated in a moist chamber at $37{ }^{\circ} \mathrm{C}$, washed with distilled water, and stained with $20 \%$ Giemsa for $17 \mathrm{~min}, \mathrm{pH}$ 6.8. $\mathrm{AgNO}_{3}$ staining of 
Table 1 Restriction enzymes and chromosomes digestion conditions

\begin{tabular}{llll}
\hline Name & $\begin{array}{l}\text { Recognition } \\
\text { sequence }\end{array}$ & $\begin{array}{l}\text { Final } \\
\text { concentration }(\mathrm{U} / \mu \mathrm{l})\end{array}$ & $\begin{array}{l}\text { Optimal incubation } \\
\text { time at } 37^{\circ} \mathrm{C}(\mathrm{h})\end{array}$ \\
\hline AluI & AG $\downarrow \mathrm{CT}$ & 0.3 & 1 \\
DdeI & C $\downarrow$ TNAG & 0.5 & 2.3 \\
Hae $\mathrm{III}$ & GG $\downarrow \mathrm{CC}$ & 1.5 & 6 \\
HinfI & G $\downarrow$ ANTC & 1.5 & 4.5 \\
MboI & $\downarrow$ GATC & 1.5 & 8 \\
\hline
\end{tabular}

the NORs was performed according to Howell and Black (1980). The $\mathrm{CMA}_{3}$ fluorescence banding was performed as described by Sola et al. (1992).

\section{FISH and PRINS}

Telomeric DNA repeats were detected by FISH using a telomere Peptide Nucleic Acid (PNA) probe conjugated with FITC (DAKO, Denmark) according to the manufacturer's protocol. Chromosomal DNA was thermally denatured at $86{ }^{\circ} \mathrm{C}$ for 3 min under the coverslip in the presence of the PNA probe. Hybridization took place in the darkness at room temperature for $60 \mathrm{~min}$.

Fluorescence in situ hybridization (FISH) with $28 \mathrm{~S}$ rDNA probe was performed according to Fujiwara et al. (1998) with slight modification (Kirtiklis et al. 2014). A 28S rDNA probe was obtained via PCR with forward primer F8-28S: 5'-TGAAATACCACTACTCTTATCGTT-3' and reverse primer R8-28S: 5'-GGATTCTGACTTA GAGGCGTTCAG-3' (Zardoya and Meyer 1996). A $50 \mu 1$ reaction mix with $1.0 \mu \mathrm{M}$ of each of the mentioned above primers, $25 \mu \mathrm{l}$ of GoTaq Master Mix (Promega, USA), $1 \mu \mathrm{l}$ of DNA template and nuclease-free water was prepared. PCR product, obtained after 35 cycles of amplification and annealing at $55{ }^{\circ} \mathrm{C}$, was purified using the GeneElute PCR Clean-Up Kit (Sigma, USA), then labeled with Biotin-16dUTP by nick-translation method (Roche). In situ hybridization with $150 \mathrm{ng}$ of rDNA probe per slide was performed with RNase-pretreated and formamide-denaturated chromosome slides. Post-hybridization wash was performed at $37{ }^{\circ} \mathrm{C}$ for $20 \mathrm{~min}$. A detection of rDNA signals were done using avidin-FITC (Roche, Germany).

Primed in situ (PRINS) reaction was carried out according to Ocalewicz et al. (2008). For the chromosomal localization of $5 \mathrm{~S}$ rDNA sequences, Rhodamine PRINS Labeling kit (Roche, Manheim, Germany) and two primer sequences enabling detection of 5S rDNA: A: $\left(5^{\prime}\right.$-TAC GCCCGATCTCGTCCGATC- $\left.3^{\prime}\right)$ and B: (5'-CAGGCTG GTATGGCCGTAAGC- $3^{\prime}$ ) were used. After reaction, the slides were transferred to a stop buffer (50 mM EDTA, $50 \mathrm{mM} \mathrm{NaCl}, \mathrm{pH}=8$ ) for $5 \mathrm{~min}$ at $65^{\circ} \mathrm{C}$ and washed in Tween 20 in $4 \times \mathrm{SSC}$ at room temperature. Chromosomes were counterstained with $25 \mu \mathrm{l}(1.5 \mu \mathrm{g} / \mathrm{ml})$ DAPI in an antifade solution Vectashield.

\section{Microscopy and image processing}

Metaphase plates were examined using Nikon Optiphot, Nikon 90i (Nikon, Japan) and Zeiss Axio Imager.A1 (Zeiss, Germany) microscopes equipped with epi-fluorescence and the digital cameras. Pictures were acquired using a monochromatic ProgRes MFcool camera (Jenoptic, Germany) controlled by a Lucia software (Laboratory Imaging, Czech Republic). Images of chromosomes after PNA-FISH and PRINS were captured and the electronic processing of the images was performed using Band View/ FISH View software (Applied Spectral Imaging, Israel). Post-processing elaboration of all the pictures was made based using CorelDRAW Graphics Suite 11 (Corel Corporation, Canada). The metaphase chromosomes were karyotyped by size and position of the centromere in according to Levan et al. (1964). Metacentrics (m) and submetacentrics (sm) were classified as bi-armed, whereas subtelocentrics (st) and acrocentrics (a) as mono-armed chromosomes.

\section{Results}

The diploid chromosome number of the brook trout individuals under study was invariably $2 \mathrm{n}=84$. The karyotype comprised $14 \mathrm{~m}$, two sm and 68 st-a chromosomes $(\mathrm{NF}=100)$ (Fig. 1).

Figure 2 presents patterns of different chromatin types in the karyotype. C-banding revealed the blocks of constitutive heterochromatin located in the pericentromeric regions of all chromosomes. Also telomeric regions of two pairs of $\mathrm{m}$ chromosomes (Nos. 1 and 5) and four pairs of a chromosomes (Nos. 30, 34, 37 and 40) were C-positive. Moreover, entire short $(p)$ arms of the chromosome pair No. 9 were entirely hetrochromatinized/C-positive (Fig. 1a). Pericentromeric regions of the chromosomes were completely digested by $A l u \mathrm{I}$ treatment but remained untouched by DdeI, HaeIII and MboI (Fig. 1b, c, d, e). HinfI digested pericentromeric region of the largest a chromosome pair (No. 11) only (Fig. 1f). Furthermore, entire C-band-positive $p$ arms of the chromosome pair No. 9 were digested by AluI, HaeIII and MboI (Fig. 1b, d, e). Large blocks of the undigested chromatin were situated at the distal parts of all chromosomes 
Fig. 1 Karyotype of the brook trout (Salvelinus fontinalis) arranged from C-banded (a), Giemsa-stained after digestion with AluI (b), DdeI (c), HaeIII (d), MboI (e) and HinfI (f) restriction endonuclease chromosomes. Scale bar $=10 \mu \mathrm{m}$ (a)

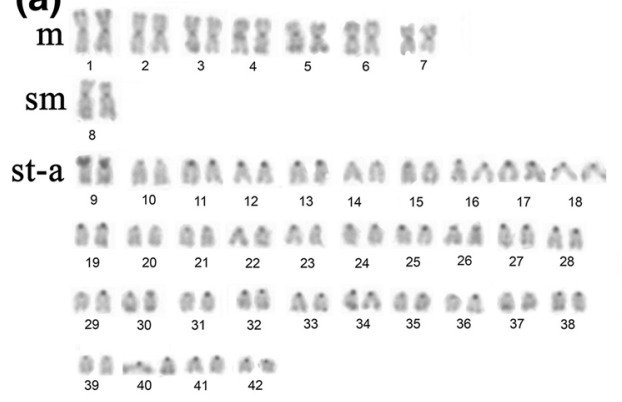

(c)

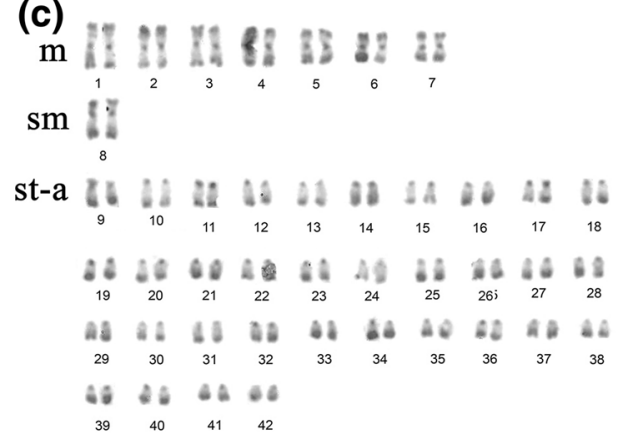

(e)

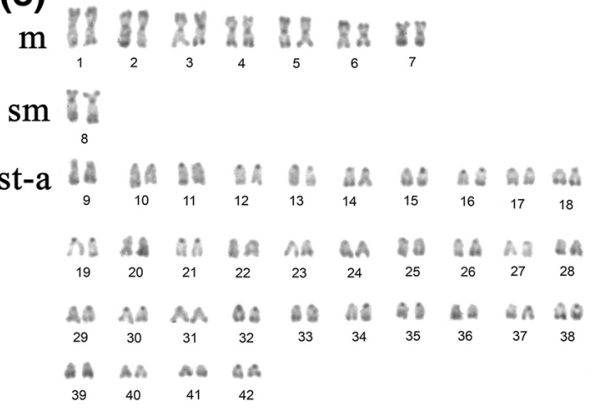

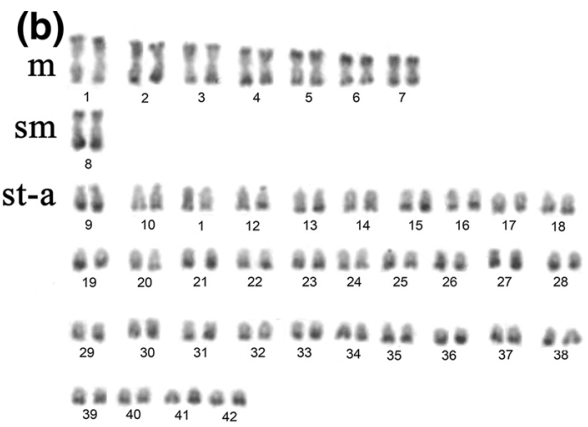

(d)

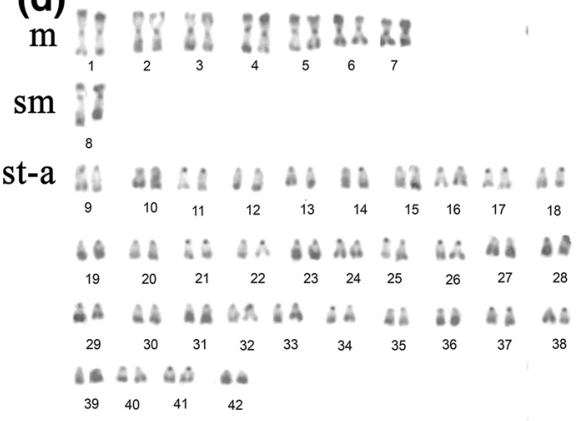

(f)

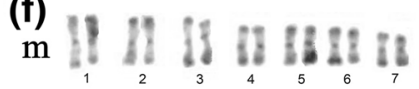

sm

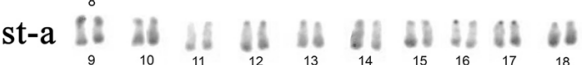

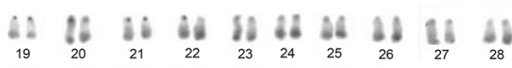

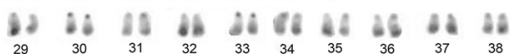

A) MA AA AL after AluI (Fig. 1b), DdeI (Fig. 1c), HaeIII (Fig. 1d) and HinfI (Fig. 1f) treatments. After MboI digestion only small telomeric bands remained untouched at all chromosomes (Fig. 1e).

All had pericentromeric bright DAPI signals. DAPI positive telomeric regions were observed in the $q$ arms of two $m$ chromosomes No. 5 in the female and only one such chromosome in the male karyotype (Fig. 2). These chromosomes were previously identified as $\mathrm{X}$ chromosomes (Phillips et al. 2001; Ocalewicz et al. 2004; Phillips 2013). Moreover, entire $p$ arms of st-a chromosomes No. 9 were DAPI-positive and a small telomeric DAPI-positive block on the $p$ arm of the largest $\mathrm{m}$ chromosome pair (No. 1) was visible (Fig. 2).

Ag-NORs have been present in 3-6 sites in the karyotype at the chromosome pairs Nos. 3, 10, 11, 26 and 29. One pair of small-sized a chromosomes (No. 29) was $\mathrm{AgNO}_{3}$-positive in all studied metaphases (Fig. 3).
Chromomycin $\mathrm{A}_{3}\left(\mathrm{CMA}_{3}\right)$-positive regions were found to be polymorphic in size and number revealing 10-20 chromosomes possessing GC-rich blocks per cell. $\mathrm{CMA}_{3}$ signals were found on one m pair (No. 3) and eight or nine st-a chromosome pairs, in some individuals only on one homologue (Fig. 3a). Size polymorphism was recognized in two individuals due to amplification and/or deletions of the $\mathrm{CMA}_{3}$-positive region (pairs Nos. 3 and 29) (Fig. 3b, c). Three individuals had two $\mathrm{CMA}_{3}$-positive blocks on distal regions of both arms of chromosome No. 3 (Fig. 3b). $\mathrm{AgNO}_{3}$-staining performed sequentially after $\mathrm{CMA}_{3}$-staining revealed that $\mathrm{Ag}$-positive NORs always occurred only within $\mathrm{CMA}_{3}$-positive sites while many small $\mathrm{CMA}_{3}$-positive sites never stained by $\mathrm{AgNO}_{3}$.

After FISH with 28S rDNA probe, hybridization signals were mainly observed on one or both arms of 24 chromosomes including one $\mathrm{m}$, one sm and 22 st-a chromosomes (Fig. 4). Fluorescence intensity and number of the 


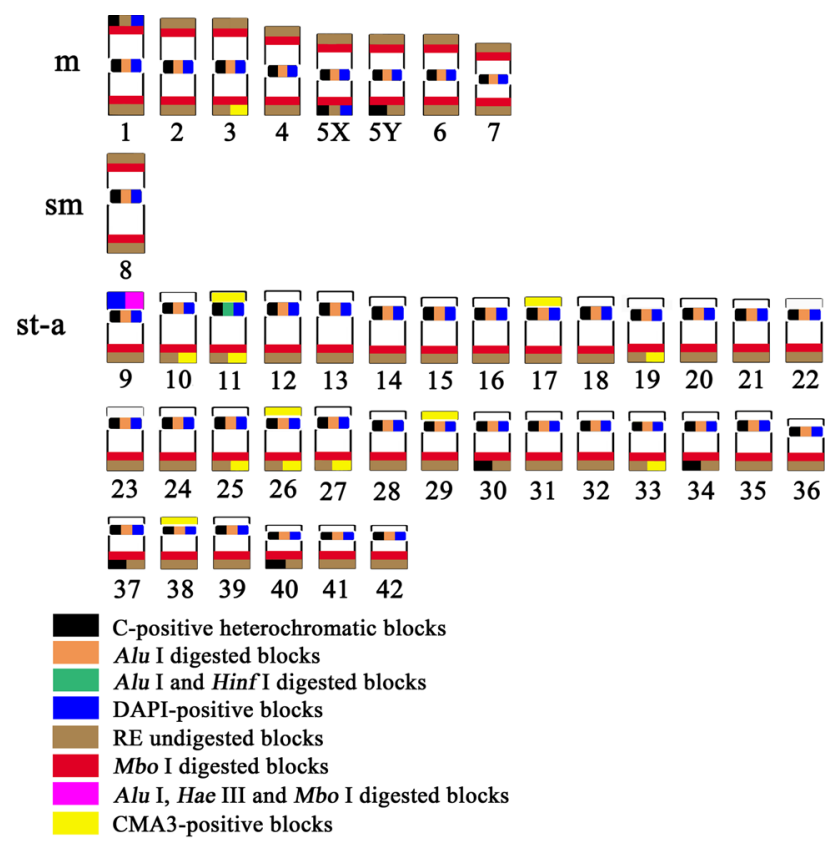

Fig. 2 Ideogram representing the distribution of heterochromatin in the chromosomes of the brook trout (Salvelinus fontinalis) from Poland

chromosomes with fluorescent sites modestly varied intraindividually in the range from 22 to 26 chromosomes $(+/-)$ two signals placed on $p$ arms of two st-a chromosomes, signals observed on both arms or only $p$ arm of the chromosome No. 11 (Fig. 4). No differences between males and females were detected.

Application of FISH with PNA telomere probe revealed telomeric signals at the ends of the sister chromatids from all chromosomes. Additionally, interstitially located telomeric sequences were observed in the pericentromeric region of the st chromosome No. $11 p$ arm. Sequentially performed PNA-FISH and $\mathrm{AgNO}_{3}$-staining exhibited region between terminal and interstitial telomeric signals overlapped by the Ag-positive sites (Fig. 3d).

Primed in situ (PRINS) with primers enabling 5S rDNA sequence amplification revealed that clusters of $5 \mathrm{~S}$ sequences were located on the whole $p$ DAPI-positive arms of the st-a chromosome pair No. 9 (Fig. 4). $5 \mathrm{~S}$ regions were not associated with NORs.

\section{Discussion}

The karyotypic macrostructure found in $S$. fontinalis $(2 \mathrm{n}=84, \mathrm{FN}=100)$ from Polish fish farm confirms the previous analyses of North American (Lee and Wright 1981), Japanese (Ueda and Ojima 1983) and British stocks (Hartley 1991).

Application of the conventional cytogenetic techniques enabled characteristics of the heterochromatin variation in (a)

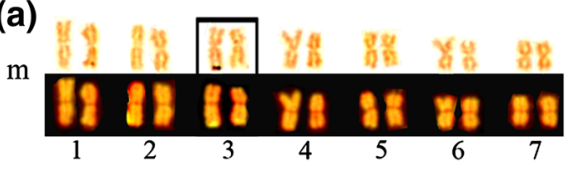

$\operatorname{sm} \frac{1}{8}$
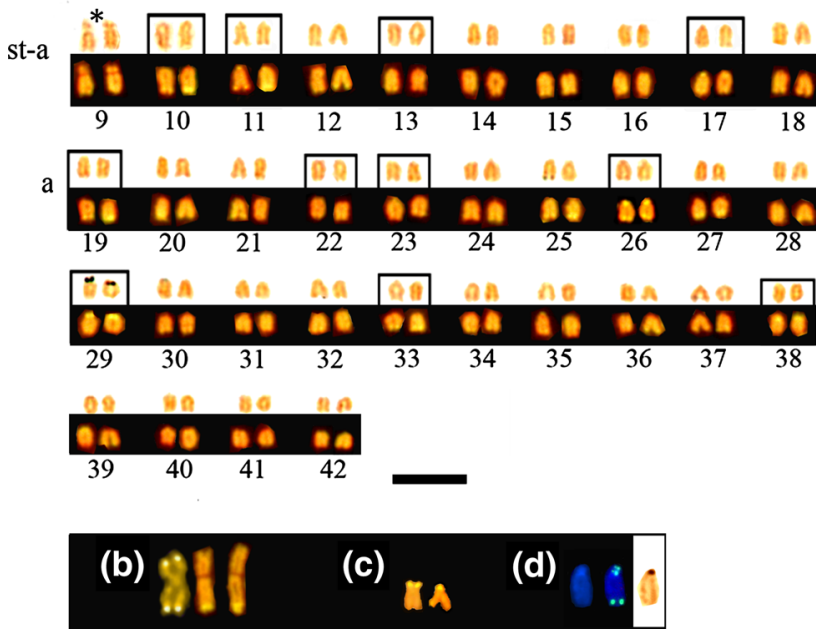

Fig. 3 Karyotype of the brook trout (Salvelinus fontinalis) arranged from silver-stained (top row) and chromomycin $\mathrm{A}_{3}$-stained $\left(\mathrm{CMA}_{3}\right)$ (bottom row) chromosomes (a). Chromosome pairs bearing $28 \mathrm{~S}$ rDNA are framed, and the chromosome pair with 5S rDNA on the $p$ arm is indicated with asterisk. Examples of the chromosome pairs Nos. 3 (b) and 29 (c) showing size polymorphism of GC-rich blocks stained with $\mathrm{CMA}_{3}$ and chromosome No. 11 (d) displaying internal telomeric site after telomere PNA hybridization (in the middle, DAPI on the left $)$ which coincided with active $\mathrm{NOR}\left(\mathrm{AgNO}_{3}\right.$ staining on the right). Scale bar $=10 \mu \mathrm{m}$

the brook trout. Several types of the C-banded heterochromatin built with predominance of AT base pairs (DAPI-positive), $\mathrm{GC}$ base pairs $\left(\mathrm{CMA}_{3}\right.$-positive) and resistant to particular restriction endonucleases grouped in three areas of the brook trout genome including telomeric sites, pericentromeric regions and NORs were distinguished (Figs. 1, 2, 3). Most of the brook trout chromatin is abundant in the DNA sequences recognized by the restriction enzymes used in the present study. Chromatin resistant to all endonucleases was restricted to the telomeric regions. In turn, centromeric regions of the brook trout chromosomes were prone to the digestion of $A l u \mathrm{I}$ enzyme, only (Fig. 1b). The same properties of centromeric and telomeric chromatin have been reported by Hartley (1991) in the cultured brook trout and the Arctic char (Salvelinus alpinus) from England.

About half of the cytogenetically examined salmonid species including e.g. brown trout (Salmo trutta), whitefish (Coregonus lavaretus), vendace (Coregonus albula) and the European grayling (Thymallus thymallus) exhibit a multiple NOR-bearing pairs of chromosome (Phillips and 
Fig. 4 Metaphase plates of Salvelinus fontinalis after DAPI staining (a), probed with $28 \mathrm{~S}$ rDNA (b) and schematic representation of the chromosomes carrying $28 \mathrm{~S}$ rDNA sequences (black) (c); chromosome pair bearing $5 \mathrm{~S}$ rDNA after DAPI staining is shown in the inset in a and after PRINS in b. Arrows point $5 \mathrm{~S}$ rDNA bearing pair No. 9. Scale bar $=10 \mu \mathrm{m}$
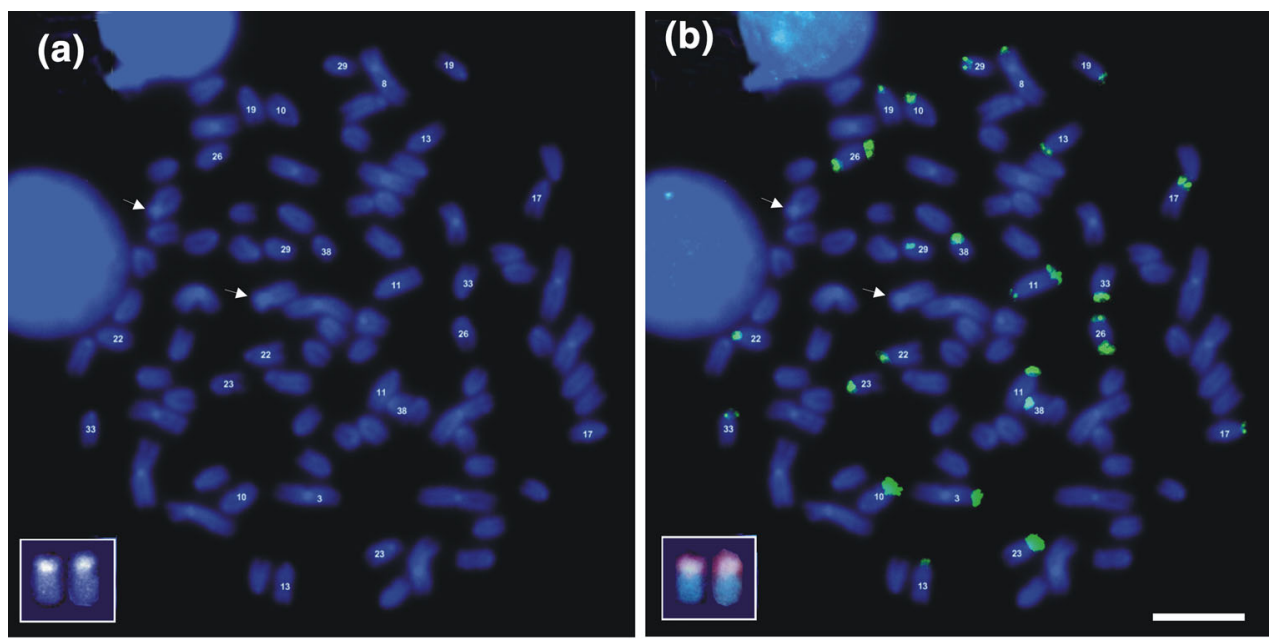

(c)

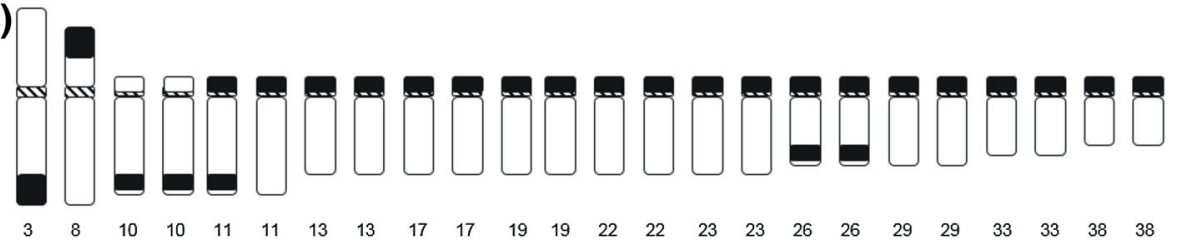

- centromere
- -rDNA sites

2013; Ocalewicz et al. 2013) it is not excluded that interstitial insertions of the telomeric DNA repeats may appear in the course of rearrangements responsible for the redistribution of the rDNAs and GC-rich chromatin. However, ITSs are also considered as a fragile sites for the recombination (Ashley and Ward 1993) and potentially may cause redistribution of the DNA sequences, what in turn could result in the polymorphisms of size and location of the GC-rich chromatin in Salvelinus species.

In teleost fish species GC-rich $\mathrm{CMA}_{3}$ positive sites correspond to the Ag-NOR (e.g. Ráb et al. 1999; Jankun et al. 2003; among others). This is also true for the brook trout studied here showing up to six NORs that are composed of the GC-rich block of chromatin. It has been also observed that not all NORs were active during the last interphase in the studied brook trout (Fig. 3a). This is the manifestation of rRNA gene dosage control. Such system operates in animals to regulate the number of active rRNA genes according to the physiological needs of the cell (McStay and Grummt 2008).

It is very interesting that rDNA sequences that are part of NORs were frequently found on the other than Ag-NORcarrying brook trout chromosomes (Figs. 3, 4). Supernumerary rDNA loci has been also identified in the brook trout from other populations (Fujiwara et al. 1998; Phillips and Reed 1996) and the lake trout (Reed and Phillips 1995). In Coregonus fontanae, apart from the complete 
6-10 NORs about 30 rDNA loci located outside NORs were observed. A chromosomal co-localization of the retrotransposon and the rDNAs suggests a retrotransposition of the part of $45 \mathrm{~S}$ rDNA unit as mechanism responsible for the multiplication and redistribution of the rDNA loci (Symonova et al. 2013). Thus, this may suggest that also in the brook trout most of the supernumerary $28 \mathrm{~S}$ rDNA hybridization signals were originated from the ATrich pericentromeric heterochromatin which contain transposable elements. Based on data from several organisms, rRNA gene families seem to evolve according to a combination of the evolutionary processes of birth-anddeath and concerted evolution (Rooney and Ward 2005; Eickbush and Eickbush 2007), which could explain the variability observed among related taxa.

In contrast to $28 \mathrm{~S}$ rDNA sequences, clusters of the non-nucleolus-forming 5S rDNA elements were observed only on one chromosome pair in the brook trout genome. This characteristics is not common for the other chars which rather show multiple locations of the 5S rRNA genes (Phillips et al. 2002). Although, co-localization of the minor and major rDNA loci has been described in several salmonid species (Pendas et al. 1994; Moran et al. 1996) such synteny was excluded in the brook trout.

In conclusion, the present study has shown that a combination of conventional (C-banding, $\mathrm{AgNO}_{3^{-}}$and $\mathrm{CMA}_{3}-$ bandings as well as chromosomal digestion with RE) and molecular cytogenetic techniques (PRINS with primer sequences enabling detection of 5S rDNA and FISH with telomere PNA and 28S rDNA probes) provided original data on the genomic organization of the brook trout chromosomes including distribution and structure of heterochromatin, location of NORs, their activity and physical mapping of NOR-related and the non-nucleolus-forming rDNA sequences.

Acknowledgments This work was supported by project No. 18.610.003-300, financed by the University of Warmia and Mazury in Olsztyn, Poland.

Open Access This article is distributed under the terms of the Creative Commons Attribution 4.0 International License (http:// creativecommons.org/licenses/by/4.0/), which permits unrestricted use, distribution, and reproduction in any medium, provided you give appropriate credit to the original author(s) and the source, provide a link to the Creative Commons license, and indicate if changes were made.

\section{References}

Amemiya CT, Gold JR (1986) Chromomycin A stains nucleolus organizer regions of fish chromosomes. Copeia 1:226-231

Arai R (2011) Fish karyotypes. A check list. Springer, Berlin
Ashley T, Ward DC (1993) A hot spot of recombination coincides with interstitial telomeric sequence in the Armenian hamster. Cytogenet Cell Genet 62:169-171

Caputo V, Giovanott M, Nisi Cerioni P, Splendiani A, Olmo E (2009) Chromosomal study of native and hatchery trouts from Italy (Salmo trutta complex, Salmonidae): conventional and FISH analysis. Cytogenet Genome Res 124:51-62

Castro J, Rodriguez S, Padro BG, Sanchez L, Martinez P (2001) Population analysis of an unusual NOR-site polymorphism in brown trout (Salmo trutta L.). Heredity 86:291-302. doi:10. 1046/j.1365-2540.2001.00834.x

Danzmann RG, Morgan R, Jones M, Bernatchez L (1998) A major sextet of mitochondrial DNA phylogenetic assemblages extant in eastern North American brook charr (Salvelinus fontinalis): distribution and postglacial dispersal patterns. Can J Zool 76:1300-1318

Eickbush TH, Eickbush DG (2007) Finely orchestrated movements: evolution of the ribosomal RNA genes. Genetics 175:477-485. doi:10.1534/genetics.107.071399

Fischer GJ, Held J, Hartleb C, Malison J (2009) Evaluation of brook trout production in a coldwater recycle aquaculture system. Aquac Eng 41:109-113

FishBase (2015) Fish identification. Genus Salvelinus. http://www. fishbase.org/identification/SpeciesList.php?genus=Salvelinus. Accessed 16 Apr 2015

Frolov SV, Frolova VN (2004) Karyological differentiation of north Dolly Varden and sympatric chars of the genus Salvelinus in northeastern Russia. Environ Biol Fish 69:441-447. doi:10.1007/ 978-94-007-0983-6_37

Fujiwara A, Abe S, Yamaha E, Yamazaki F, Yoshida MC (1998) Chromosomal localization and heterochromatin association of ribosomal regions in salmonids fishes. Chromosome Res 6:463-471. doi:10.1023/A:1009200428369

Grewe PM, Billington N, Hebert PN (1990) Phylogenetic relationships among members of Salvelinus inferred from mitochondrial DNA divergence. Can J Fish Aquat Sci 47:984-991

Hartley SE (1991) C, Q, and restriction enzyme banding of the chromosome in brook trout (Salvelinus fontinalis) and arctic charr (Salvelinus alpinus). Hereditas 114:253-261. doi:10.1111/ j.1601-5223.1991.tb00332.x

Howell WM, Black DA (1980) Controlled silver staining of nucleolus organizer regions with a protective colloidal developer: a 1-step method. Experientia 36:1014-1015. doi:10.1007/BF01953855

Jankun M, Ocalewicz K, Woznicki P (1998) Replication, C- and fluorescent chromosome banding patterns in European whitefish, Coregonus lavaretus L. Hereditas 128:195-199. doi:10.1111/j. 1601-5223.1998.00195.x

Jankun M, Martinez P, Pardo BG, Kirtiklis L, Ráb P, Rábova M, Sanchez L (2001) Ribosomal genes in Coregonid fishes (Coregonus lavaretus, C. albula and C. peled) (Salmonidae): single and multiple nucleolus organizer regions. Heredity 87:672-679. doi:10.1046/j.1365-2540.2001.00964.x

Jankun M, Ocalewicz K, Padro BG, Martinez P, Woznicki P, Sanchez L (2003) Chromosomal characteristics of rDNA in European grayling Thymallus thymallus (Salmonidae). Genetica 119:219-224. doi:10.1023/A:1026022415908

Jankun M, Ocalewicz K, Mochol M (2004) Chromosome banding studies by replication and restriction enzyme treatment in vendace (Coregonus albula) (Salmonidae, Salmoniformes). Folia biol Krakow 52:47-51

Jankun M, Woznicki P, Ocalewicz K, Furgala-Selezniow G (2007) Chromosomal evolution in the three species of Holarctic fish of genus Coregonus (Salmoniformes). In: Jankun M. et al. (eds) Biology and management of coregonid fishes-2005, Advances in Limnology, vol 60. E Schweizerbart'sche Verlagsbuchhandlung, Stuttgart, Germany, pp 25-37 
Kirtiklis L, Ocalewicz K, Wiechowska M, Boroń A, Hliwa P (2014) Molecular cytogenetic study of the European bitterling Rhodeus amarus (Teleostei: Cyprinidae: Acheilognathinae). Genetica 142:141-148. doi:10.1007/s10709-014-9761-x

Lee GM, Wright JE Jr (1981) Mitotic and meiotic analysis of brook trout Salvelinus fontinalis. J Hered 72:321-327

Levan A, Fredga K, Sandberg AA (1964) Nomenclature for centromeric position on chromosomes. Hereditas 52:201-220. doi:10.1111/j.1601-5223.1964.tb01953.x

Macqueen DJ, Johnston IA (2014) A well-constrained estimate for the timing of the salmonid whole genome duplication reveals major decoupling from species diversification. Proc Biol Sci 281(1778):20132881. doi:10.1098/rspb.2013.2881

McStay B, Grummt I (2008) The epigenetics of rRNA genes: from molecular to chromosome biology. Annu Rev Cell Dev Biol 24:131-157. doi:10.1146/annurev.cellbio.24.110707.175259

Michalik O, Dobosz S, Wójcik I, Zalewski T, Ocalewicz K (2014) Use of eggs derived from the interspecific charr hybrids to induce androgenetic development of the brook charr (Salvelinus fontinalis Mitchill 1814). Reprod Domest Anim 49:191-196

Moran P, Martinez JL, Garcia-Vazquez E, Pendas AM (1996) Sex chromosome linkage of $5 \mathrm{~S}$ rDNA in rainbow trout (Oncorhynchus mykiss). Cytogenet Cell Genet 75:145-150. doi:10. $1159 / 000134466$

Nelson JS (2006) Fishes of the world, 4th edn. Wiley, New York

Ocalewicz K (2013) Telomeres in fishes. Cytogenet Genome Res 141:114-125. doi:10.1159/000354278

Ocalewicz K, Dobosz S (2009) Karyotype variation in the albino rainbow trout (Oncorhynchus mykiss (Walbaum)). Genome 52:347-352. doi:10.1139/G09-009

Ocalewicz K, Śliwińska A, Jankun M (2004) Autosomal localization of internal telomeric sites (ITS) in brook trout, Salvelinus fontinalis (Pisces, Salmonidae). Cytogenet Genome Res 105:79-82. doi:10.1159/000078012

Ocalewicz K, Woznicki P, Jankun M (2008) Mapping of rDNA genes and telomeric sequences in Danube salmon (Hucho hucho) chromosomes using primed in situ labeling technique (PRINS). Genetica 134:199-203. doi:10.1007/s10709-007-9225-7

Ocalewicz K, Furgala-Selezniow G, Szmyt M, Lisboa R, Kucinski M, Lejk AM, Jankun M (2013) Pericentromeric location of the telomeric DNA sequences on the European grayling chromosomes. Genetica 141:409-416. doi:10.1007/s10709-013-9740-7

Oliveira C, Foresti F, Rigolino MG, Tabata YA (1995) Synaptonemal complex analysis in spermatocytes and oocytes of rainbow trout, Oncorhynchus mykiss (Pisces, Salmonidae). The process of autosome and sex chromosome synapsis. Chromosome Res 3:182-190

Pendas AM, Moran P, Freije JP, Garcia-Vazquez E (1994) Chromosomal mapping and nucleotide sequence of two tandem repeats of Atlantic salmon 5S rDNA. Cytogenet Cell Genet 67:31-36. doi:10.1159/000133792

Phillips RB (2013) Evolution of the sex chromosomes in salmonid fishes. Cytogenet Genome Res 141:177-185. doi:10.1159/ 000355149

Phillips RB, Ihssen PE (1985a) Identification of sex chromosomes in lake trout (Salvelinus namaycush). Cytogenet Cell Genet 39:14-18

Phillips RB, Ihssen PE (1985b) Chromosome banding in salmonid fish: nucleolar organizer regions in Salmo and Salvelinus. Can J Genet Cytol 27:433-440. doi:10.1139/g85-064

Phillips RB, Ihssen PE (1986) Inheritance of Q band chromosomal polymorphism in lake trout (Salvelinus namaycush). J Hered 77:93-97

Phillips RB, Ráb P (2001) Chromosome evolution in the Salmonidae (Pisces): an update. Biol Rev 76:1-25
Phillips RB, Reed KM (1996) Application of fluorescence in situ hybridization (FISH) to fish genetics. Aquaculture 140:197-216

Phillips RB, Pleyte KA, Ihssen PE (1989) Patterns of chromosomal nucleolar organizer region (NOR) variation in fishes of the genus Salvelinus. Copeia 1:47-53

Phillips RB, Konkol NR, Reed KM, Stein JD (2001) Chromosome painting supports lack of homology among sex chromosomes in Oncorhynchus, Salmo, and Salvelinus (Salmonidae). Genetica 111:119-123

Phillips RB, Matsuoka MP, Reed KM (2002) Characterization of charr chromosomes using fluorescence in situ hybridization. Environ Biol Fish 64:223-228. doi:10.1007/978-94-017-1352-8_ 20

Pomianowski K, Jankun M, Ocalewicz K (2012) Detection of interstitial telomeric sequences in the Arctic charr (Salvelinus alpinus, Linnaeus 1758) (Teleostei, Salmonidae). Genome 55:25-32. doi:10.1139/g11-073

Ráb P, Rábova M, Reed KM, Phillips RB (1999) Chromosomal characteristics of ribosomal DNA in the primitive semionotiform fish, longnose gar Lepisosteus osseus. Chromosome Res 7:475-480

Reed KM, Phillips RB (1995) Molecular cytogenetic analysis of the double-CMA $\mathrm{C}_{3}$ chromosome of lake trout, Salvelinus namaycush. Cytogenet Cell Genet 70:104-107

Reed KM, Phillips RB (1997) Polymorphism of the nucleolus organizer region (NOR) on the putative sex chromosomes of Arctic charr (Salvelinus alpinus) is not sex related. Chrom Res 5:221-227. doi:10.1023/A:1018411417816

Reed KM, Phillips RB (2000) Structure and organization of the rDNA intergenic spacer in lake trout (Salvelinus namaycush). Chromosome Res 8:5-16. doi:10.1023/A:1009214800251

Rooney AP, Ward TJ (2005) Evolution of a large ribosomal RNA multigene family in filamentous fungi: birth and death of a concerted evolution paradigm. Proc Natl Acad Sci U S A 102:5084-5089. doi:10.1073/pnas.0409689102

Sakamoto T, Danzmann RG, Gharbi K, Howard P, Ozaki A et al (2000) A microsatellite linkage map of rainbow trout (Oncorhynchus mykiss) characterized by large sex-specific differences in recombination rates. Genetics 155:1331-1345

Sola L, Rossi AR, Iaselli V, Rasch EM, Monaco PJ (1992) Cytogenetics of bisexual/unisexual species of Poecilia. II. Analysis of heterochromatin and nucleolar organizer regions in Poecilia mexicana by C-banding and DAPI, quinacrine, chromomycin $\mathrm{A}_{3}$, and silver staining. Cytogenet Cell Genet 60:229-235. doi:10.1159/000133346

Sumner AT (1972) A simple technique for demonstrating centromeric heterochromatin. Exp Cell Res 75:304-306. doi:10.1016/00144827(72)90558-7

Symonova R, Majtanova Z, Sember A, Staaks GBO, Bohlen J, Freyhof J, Rábova M, Ráb P (2013) Genome differentiation in a species pair of coregonine fishes: an extremely rapid speciation driven by stress-activated retrotransposons mediating extensive ribosomal DNA multiplications. BMC Evol Biol 13:42. doi:10. 1186/1471-2148-13-42

Ueda T, Ojima Y (1983) Karyotypes with C-banding patterns of two species in the genus Salvelinus of the family Salmonidae. Proc Jpn Acad 59B:343-346

Zardoya R, Meyer A (1996) Evolutionary relationships of the coelacanth, lungfishes, and tetrapods based on the $28 \mathrm{~S}$ ribosomal RNA gene. Proc Natl Acad Sci U S A 93:5449-5454. doi:10. 1073/pnas.93.11.5449

Zhuo L, Reed KM, Phillips RB (1995) Hypervariability of ribosomal DNA at multiple chromosomal sites in lake trout (Salvelinus namaycush). Genome 38:487-496. doi:10.1139/g95-064 